\title{
Cation Exchange as a Mechanism to Engineer Polarity in Layered Perovskites.
}

\author{
Tong Zhu ${ }^{\dagger}$, Guru Khalsa ${ }^{\text {Il }}$, Dana M. Havas ${ }^{\mathbb{q}}$, Alexandra S. Gibbs ${ }^{\ddagger}$, Weiguo Zhang ${ }^{\S}$, P. Shiv Halasyama- \\ $\mathrm{ni}^{\S}$, Nicole A. Benedek ${ }^{\mathbb{I} *}$ and Michael A. Hayward ${ }^{\dagger *}$

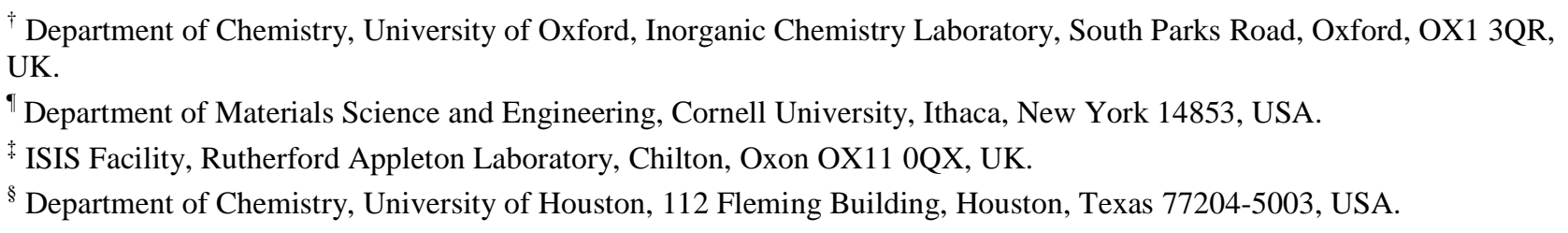

Cation exchange reactions performed on the $n=2$ Dion-Jacobson phases $\mathrm{RbNdNb}_{2} \mathrm{O}_{7}$ and $\mathrm{RbNdTa}_{2} \mathrm{O}_{7}$, using $\mathrm{LiNO}_{3}$ and $\mathrm{NaNO}_{3}$, yield the corresponding $\mathrm{LiNdM}_{2} \mathrm{O}_{7}$ and $\mathrm{NaNdM}_{2} \mathrm{O}_{7}(\mathrm{M}=\mathrm{Nb}$, Ta) phases. Synchrotron X-ray and neutron powder diffraction data, in combination with second-harmonic generation data and supported by first-principles DFT calculations, reveal that the $\mathrm{LiNdM}_{2} \mathrm{O}_{7}$ phases adopt $n=2$ Ruddlesden-Popper type structures with an $a^{-} a^{-} c^{+} /-\left(a^{-} a^{-} c^{+}\right)$distortion described in the polar space group $B 2 \mathrm{~cm}$. In contrast, the $\mathrm{NaNdM}_{2} \mathrm{O}_{7}$ phases adopt $n=2$ Ruddlesden-Popper type structures with an $a^{-} b^{0} c^{0} / b^{0} a^{-} c^{0}$ distortion, described in the centrosymmetric space group $P 4_{2} / m n m$. The differing structures adopted by the $\mathrm{LiNdM}_{2} \mathrm{O}_{7}$ and $\mathrm{NaNdM}_{2} \mathrm{O}_{7}$ phases are rationalized on the basis of a competition between i) optimizing the size of the $\mathrm{Li} / \mathrm{Na}$ coordination site via octahedral tilting and ii) ordering the $\mathrm{Na} / \mathrm{Li}$ cations within the $(\mathrm{Li} / \mathrm{Na}) \mathrm{O}_{2}$ sheets to minimize cation-cation repulsion - the former appears to be the dominant factor for the $\mathrm{Li}$ phases and the latter factor dominates for the $\mathrm{Na}$ phases. The strong A'-cation dependence of the tilting distortions adopted by the $\mathrm{A}^{\prime} \mathrm{NdM}_{2} \mathrm{O}_{7}$ phases suggests that by careful selection of the substituting cation the tilting distortions of layered perovskite phases can be rationally tuned to adopt polar configurations, and thus new ferroelectric phases can be synthesized.

\section{Introduction}

Ferroelectric materials - those which exhibit a spontaneous, switchable electrical polarization - are utilized in a wide variety of technical applications. ${ }^{1}$ However the discovery and design of new ferroelectric materials is challenging because a prerequisite for a material to exhibit ferroelectric behavior is the adoption of a non-centrosymmetric (NCS) polar crystal structure. $^{2-3}$ This is a taxing requirement because, in general, symmetric packing schemes are more efficient than asymmetric arrangements, and thus NCS structures tend to be energetically disfavored compared to centrosymmetric alternatives.

The most common approach used to try to stabilize NCS structures is the exploitation of second-order Jahn-Teller (SOJT) distortions to break symmetry locally. For example, by including either octahedrally coordinated $d^{0}$ transition metal cations (e.g. $\mathrm{Ti}^{4+}$ in $\left.\mathrm{BaTiO}_{3}\right)^{4-7}$ or post-transition elements with $\mathrm{ns}^{2}$ electronic configurations (e.g. $\mathrm{Bi}^{3+}$ in $\left.\mathrm{BiFeO}_{3}\right)^{8-13} \mathrm{SOJT}$ interactions can be used to favor NCS structures. However this route restricts which elements can be included in ferroelectric materials, and is especially limiting if the desire is to combine ferroelectricity with ferromagnetism to prepare magnetoelectric multiferroic materials. ${ }^{14}$

Recently theoretical analysis has been used to develop a strategy of harnessing the collective tilts and rotations of the octahedral units in perovskite phases and their layered analogues to break inversion symmetry. ${ }^{15-17}$ By combining two non-polar distortion modes (typically rotations around the $x$ and $y$-axes combined with rotations around the $z$-axis) a third polar distortion mode becomes allowed via the 'tri-linear' coupling mechanism. ${ }^{15,18}$ Thus the inversion symmetry of the centrosymmetric aristotype structure can be lifted by harnessing common, low-energy structural distortions, without the need to include any special chemical elements. This insight provides a rational pathway by which NCS structures can be stabilized and ferroelectric behavior induced, because the tilting distortions of perovskite lattices and their layered analogues can be controlled through simple packing effects arising from the sizes of the ions which make up a phase. ${ }^{19-21} \mathrm{~A}$ number of studies have demonstrated this behavior experimentally, most notably in the $\mathrm{A}_{3} \mathrm{~B}_{2} \mathrm{O}_{7} n=2$ Ruddlesden-Popper structure where $(\mathrm{Ca}, \mathrm{Sr})_{3} \mathrm{Ti}_{2} \mathrm{O}_{7}{ }^{22} \mathrm{Ca}_{3} \mathrm{Mn}_{2} \mathrm{O}_{7}{ }^{23}$ and $\mathrm{Sr}_{3} \mathrm{Zr}_{2} \mathrm{O}_{7}{ }^{24}$ have been shown to not only adopt NCS structures, but also ferroelectric behavior.

The tri-linear mechanism for symmetry breaking is not limited to the $n=2$ Ruddlesden-Popper framework. Recently it has been shown that it can also operate in the $\mathrm{A}^{\prime} \mathrm{AB}_{2} \mathrm{O}_{7}$ DionJacobson phases, ${ }^{25-26}$ leading to a series of polar, potentially ferroelectric materials. ${ }^{27-29}$ An additional feature of the DionJacobson phases is that they exhibit a wide variety of cation exchange reactions ${ }^{30-32}$ in which the monovalent $A^{\prime}$ cation (typically $\mathrm{Rb}^{+}$or $\mathrm{Cs}^{+}$) can be exchanged for a broad range of other cations, ${ }^{33-36}$ metal salts ${ }^{37-39}$ or complex molecules ${ }^{40-42}$ to yield phases which are often metastable and unpreparable by more direct routes. This diverse cation exchange chemistry offers a simple method to tune the tilting distortions of the Dion-Jacobson lattice and hence induce ferroelectric behavior. 


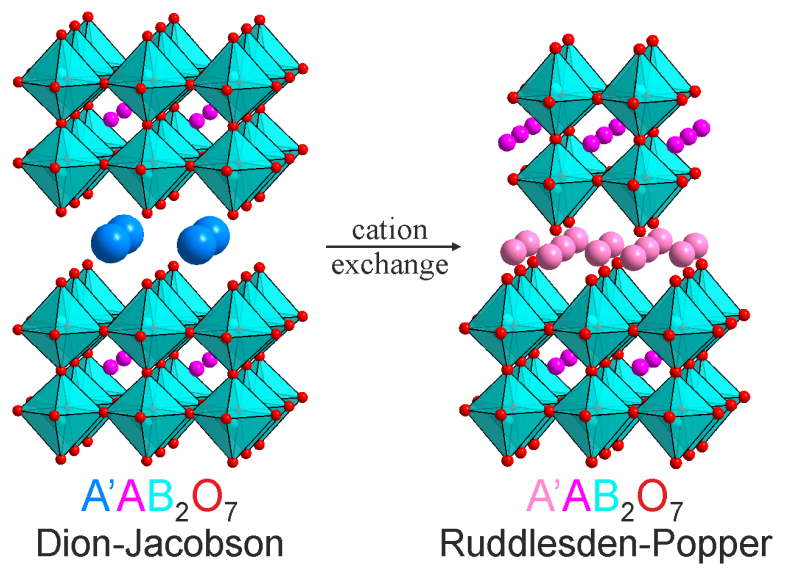

Figure 1. The structural transformation when an $\mathrm{A}^{\prime} \mathrm{AB}_{2} \mathrm{O}_{7}\left(\mathrm{~A}^{\prime}=\right.$ $\mathrm{Rb}, \mathrm{Cs})$ Dion-Jacobson phase is converted into an $\mathrm{A}^{\prime} \mathrm{AB}_{2} \mathrm{O}_{7}\left(\mathrm{~A}^{\prime}=\right.$ $\mathrm{Li}, \mathrm{Na})$ Ruddlesden-Popper phase. In the latter structure the pink A' cation sites are $50 \%$ occupied.

The simple like-for-like exchange of monovalent cations in Dion-Jacobson phases has been extensively studied and it has been observed that when the large $\mathrm{A}^{\prime}$ cations $\left(\mathrm{Rb}^{+}\right.$or $\mathrm{Cs}^{+}$for example) within the lattice are exchanged for smaller cations, such as $\mathrm{Li}^{+}$or $\mathrm{Na}^{+}$, the $\mathrm{AB}_{2} \mathrm{O}_{7}$ double perovskite sheets change their stacking arrangement from a simple 'primitive' stacking to the 'body-centered' stacking of the Ruddlesden-Popper framework. This shifting of the perovskite sheets creates a series of 4-fold, pseudo tetrahedral inter-layer coordination sites in which the small $\mathrm{Li}^{+}$and $\mathrm{Na}^{+}$cations reside, as shown in Figure 1. ${ }^{33,35,43}$ Here we describe the detailed structural characterization of $\mathrm{LiNdM}_{2} \mathrm{O}_{7}$ and $\mathrm{NaNdM}_{2} \mathrm{O}_{7}(\mathrm{M}=\mathrm{Nb}, \mathrm{Ta})$ prepared via the cation exchange of the corresponding $\mathrm{RbNdM}_{2} \mathrm{O}_{7}$ phase, and show in contrast to previous reports that both the lithium and sodium phases adopt distorted structures, with the lithium phases adopting NCS polar structures.

\section{Experimental}

Synthesis. Samples of $\mathrm{RbNdNb}_{2} \mathrm{O}_{7}$ and $\mathrm{RbNdTa}_{2} \mathrm{O}_{7}$ were prepared from $\mathrm{Rb}_{2} \mathrm{CO}_{3}(99.8 \%), \mathrm{Nd}_{2} \mathrm{O}_{3}(99.99 \%$, dried at 900 $\left.{ }^{\circ} \mathrm{C}\right)$ and $\mathrm{Nb}_{2} \mathrm{O}_{5}\left(99.9985 \%\right.$, dried at $\left.900{ }^{\circ} \mathrm{C}\right)$ or $\mathrm{Ta}_{2} \mathrm{O}_{5}$ $\left(99.993 \%\right.$, dried at $900{ }^{\circ} \mathrm{C}$ ) as described previously. ${ }^{28}$ Suitable stoichiometric ratios of the oxides were ground together in an agate pestle and mortar and then combined with a $50 \%$ excess of $\mathrm{Rb}_{2} \mathrm{CO}_{3}$ (to compensate for metal loss due to volatility at high temperature). These mixtures were then heated at $850{ }^{\circ} \mathrm{C}$ in air for $12 \mathrm{~h}$, reground, and pressed into pellets. Samples of $\mathrm{RbNdNb}_{2} \mathrm{O}_{7}$ were heated in air for four periods of $48 \mathrm{~h}$ at 1000 ${ }^{\circ} \mathrm{C}$ and a further $48 \mathrm{~h}$ at $1050{ }^{\circ} \mathrm{C}$. Samples of $\mathrm{RbNdTa}_{2} \mathrm{O}_{7}$ were heated in air for four periods of $48 \mathrm{~h}$ at $1050{ }^{\circ} \mathrm{C}$. All samples were reground and pressed into pellets between heating cycles. After heating, all samples were washed with distilled water to remove any remaining excess rubidium oxide, and then dried for $12 \mathrm{~h}$ at $140{ }^{\circ} \mathrm{C}$ in air.

Lithium and sodium cation-exchange reactions were performed by reacting $\mathrm{RbNdNb}_{2} \mathrm{O}_{7}$ and $\mathrm{RbNdTa}_{2} \mathrm{O}_{7}$ with 10 mole-equivalents of either $\mathrm{LiNO}_{3}(99.98 \%)$ or $\mathrm{NaNO}_{3}$ (>99.0\%). These mixtures were ground together and loaded into an open ended silica tube. Lithium exchange reactions were heated in air for two periods of $48 \mathrm{~h}$ at $300^{\circ} \mathrm{C}$. Sodium exchange reactions were heated in air for two periods of $48 \mathrm{~h}$ at $400{ }^{\circ} \mathrm{C}$. Reaction vessels were kept in a vertical orientation during the heating cycles as both lithium and sodium nitrate melt at the applied reaction temperatures. Between heating cycles, samples were washed with distilled water, dried for 12 $\mathrm{h}$ at $140{ }^{\circ} \mathrm{C}$ in air and mixed with a further 10 moleequivalents of lithium or sodium nitrate. After the final heating step, all samples were washed with distilled water to remove remaining lithium or sodium nitrate, and dried for $12 \mathrm{~h}$ at 140 ${ }^{\circ} \mathrm{C}$ in air. Samples of $\mathrm{NaNdNb}_{2} \mathrm{O}_{7}$ and $\mathrm{NaNdTa}_{2} \mathrm{O}_{7}$ then dried under flowing argon for $12 \mathrm{~h}$ at $300{ }^{\circ} \mathrm{C}$ to eliminate all water and then transferred into an Argon-filled glove box for storage.

Characterization. Reaction progress and final sample purity were assessed using X-ray powder diffraction data collected using a PANalytical X'pert diffractometer incorporating an $\mathrm{X}$ 'celerator position sensitive detector (monochromatic $\mathrm{Cu}$ $\mathrm{K} \alpha 1$ radiation). High-resolution synchrotron $\mathrm{X}$-ray powder diffraction data were collected using instrument I11 at Diamond Light Source Ltd. Diffraction patterns were measured using Si-calibrated X-rays with an approximate wavelength of $0.825 \AA$, from samples sealed in $0.3 \mathrm{~mm}$ diameter borosilicate glass capillaries. Neutron powder diffraction data were collected from samples contained within vanadium cans, using the HRPD diffractometer at the ISIS neutron source. Rietveld profile refinement was performed using the GSAS suite of programs. $^{44}$

The particle-size dependent second harmonic generation (SHG) response of samples was measured by grinding sintered pellets of material and then sieving the resulting powders into distinct particle size ranges $(<20,20-45,45-63,63-75,75-90$, 90-25 $\mu \mathrm{m}$ ). SHG intensity was then recorded from each particle size range and compared to a standard sample of $\alpha-\mathrm{SiO}_{2}$ in the same particle size ranges. No index matching fluid was used in any of the experiments. A detailed description of the experimental setup and process has been reported previously. ${ }^{45}$

First-Principles Calculations. The first-principles calculations were performed using the PBEsol exchange-correlation functional ${ }^{46}$ and projector augmented wave (PAW) pseudopotentials, ${ }^{47-48}$ as implemented in the VASP package. ${ }^{49-52}$ The valence electron configurations for each pseudopotential were as follows: $\mathrm{Li}-1 \mathrm{~s}^{2} 2 \mathrm{~s}^{1}, \mathrm{Na}-2 \mathrm{~s}^{2} 3 \mathrm{~s}^{1} 2 \mathrm{p}^{6}, \mathrm{Nd}-5 \mathrm{~s}^{2} 6 \mathrm{~s}^{2} 5 \mathrm{p}^{6} 5 \mathrm{~d}^{1}, \mathrm{Nb}$ $-4 s^{2} 5 s^{1} 4 p^{6} 4 d^{4}, T a-5 p^{6} 5 d^{4} 6 s^{1}$, and $O-2 s^{2} 2 p^{4}$. Good convergence of structural parameters (lattice parameters and Wyckoff positions) was achieved for a plane wave cutoff of $700 \mathrm{eV}$ and a $6 \times 6 \times 2$ Monkhorst-Pack mesh, compared to higher plane wave cutoffs and denser k-point meshes. Structural relaxations were considered converged when the force on each atom became smaller than $1 \mathrm{meV} / \mathrm{A}$.

\section{Results}

Structural Characterization of $\mathrm{LiNdNb}_{2} \mathrm{O}_{7}$ and $\mathbf{L i N d T a}_{2} \mathbf{O}_{7}$. Synchrotron X-ray and neutron powder diffraction data collected from $\mathrm{LiNdNb}_{2} \mathrm{O}_{7}$ and $\mathrm{LiNdTa}_{2} \mathrm{O}_{7}$ can be indexed using orthorhombic unit cells $\left(\mathrm{LiNdNb}_{2} \mathrm{O}_{7}: a=5.450\right.$ $\AA, b=5.397 \AA, c=20.455 \AA$ 站dTa $2 \mathrm{O}_{7}: a=5.443 \AA, b=$ $5.409 \AA, c=20.501 \AA$ ) consistent with distorted $n=2$ Ruddlesden-Popper type structures. This contrasts previous reports of an undistorted $(I 4 / \mathrm{mmm})$ structure for $\mathrm{LiNdNb}_{2} \mathrm{O}_{7}{ }^{35}$ We did not observe any evidence by diffraction for mixed cation $(\mathrm{Li} / \mathrm{Rb}) \mathrm{NdNb}_{2} \mathrm{O}_{7}$ or $(\mathrm{Li} / \mathrm{Rb}) \mathrm{NdTa}_{2} \mathrm{O}_{7}$ phases during the cation exchange reactions, with $\mathrm{RbNdM}_{2} \mathrm{O}_{7}$ starting materials converting directly to $\mathrm{LiNdM}_{2} \mathrm{O}_{7}$ product phases.

Directly determining the distortion adopted by an $n=2$ Ruddlesden-Popper phase can be challenging from powder diffraction data. To assist us, we have built on the work of Aleksandrov and Bartolome ${ }^{53}$ (who listed all the mathematically possible distortions of the $n=2$ Ruddlesden-Popper framework) by performing a symmetry analysis using 


\begin{tabular}{|c|c|c|c|c|c|}
\hline space group & tilt system & Glazer tilt & $\chi^{2}$ & wRp (\%) & $\operatorname{Rp}(\%)$ \\
\hline \multicolumn{6}{|l|}{$\mathrm{LiNdNb}_{2} \mathrm{O}_{7}$} \\
\hline$P 2_{1} n m$ & $\Phi_{1} \Phi_{2} \Psi_{z} / \Phi_{2} \Phi_{1} \Psi_{z}$ & $a^{-} b^{-} c^{+} / b^{-} a^{-} c^{+}$ & 111.3 & 16.18 & 13.35 \\
\hline$P 2 \mathrm{~cm}$ & $\Phi_{1} \Phi_{2} \Psi_{\mathrm{z}} /-\left(\Phi_{1} \Phi_{2}\right) \Psi_{\mathrm{z}}$ & $a^{-} b^{-} c^{+} /-\left(a^{-} b^{-}\right) c^{+}$ & 10.10 & 4.88 & 5.61 \\
\hline$P 2 \mathrm{~cm}$ (constrained) & $\Phi_{1} \Phi_{2} \Psi_{\mathrm{z}} /-\left(\Phi_{1} \Phi_{2}\right) \Psi_{\mathrm{z}}$ & $a^{-} b^{-} c^{+} /-\left(a^{-} b^{-}\right) c^{+}$ & 17.79 & 6.48 & 6.52 \\
\hline$B 2 \mathrm{~cm}$ & $\Phi \Phi \Psi_{\mathrm{z}} /-\left(\Phi_{1} \Phi_{2} \Psi_{\mathrm{z}}\right)$ & $a^{-} a^{-} c^{+} /-\left(a^{-} a^{-} c^{+}\right)$ & 12.78 & 5.49 & 6.04 \\
\hline \multicolumn{6}{|l|}{$\mathrm{LiNdTa}_{2} \mathrm{O}_{7}$} \\
\hline$P 2_{1} n m$ & $\Phi_{1} \Phi_{2} \Psi_{z} / \Phi_{2} \Phi_{1} \Psi_{z}$ & $a^{-} b^{-} c^{+} / b^{-} a^{-} c^{+}$ & 83.51 & 14.41 & 13.66 \\
\hline$P 2 \mathrm{~cm}$ & $\Phi_{1} \Phi_{2} \Psi_{\mathrm{z}} /-\left(\Phi_{1} \Phi_{2}\right) \Psi_{\mathrm{z}}$ & $a^{-} b^{-} c^{+} /-\left(a^{-} b^{-}\right) c^{+}$ & 4.57 & 3.37 & 4.02 \\
\hline$P 2 \mathrm{~cm}$ (constrained) & $\Phi_{1} \Phi_{2} \Psi_{\mathrm{z}} /-\left(\Phi_{1} \Phi_{2}\right) \Psi_{\mathrm{z}}$ & $a^{-} b^{-} c^{+} /-\left(a^{-} b^{-}\right) c^{+}$ & 8.52 & 4.61 & 4.73 \\
\hline$B 2 \mathrm{~cm}$ & $\Phi \Phi \Psi_{\mathrm{z}} /-\left(\Phi_{1} \Phi_{2} \Psi_{\mathrm{z}}\right)$ & $a^{-} a^{-} c^{+} /-\left(a^{-} a^{-} c^{+}\right)$ & 5.76 & 3.79 & 4.38 \\
\hline
\end{tabular}

Table 1: Fitting Statistics from the structural refinement of $\mathrm{LiNdNb}_{2} \mathrm{O}_{7}$ and $\mathrm{LiNdTa}_{2} \mathrm{O}_{7}$ against neutron powder diffraction data.

the ISODISTORT software ${ }^{54}$ to produce a list of the 'chemically plausible' distortions of the framework, listed in Table $\mathrm{S} 1$ in the supporting information. We define the 'chemically plausible' distortions as those that retain equivalence of all the $\mathrm{BO}_{6}$ octahedra in the framework, and we have henceforth assumed that $\mathrm{LiNdNb}_{2} \mathrm{O}_{7}$ and $\mathrm{LiNdTa}_{2} \mathrm{O}_{7}$ adopt one of the distorted structures listed in Table S1. For ease of comparison we will describe all distorted structures using unit cells in which the stacking direction is aligned parallel to the z-axis (column 5 in Table S1).

Particle-size dependent SHG data, shown in Figure 2, indicate that both $\mathrm{LiNdNb}_{2} \mathrm{O}_{7}$ and $\mathrm{LiNdTa}_{2} \mathrm{O}_{7}$ are SHG active, and thus adopt non-centrosymmetric crystal structures. This information allows us to eliminate all of the centrosymmetric structures in Table S1, leaving 4 non-centrosymmetric candidate space groups: $B b 2_{1} m, P 2_{1} \mathrm{~nm}, \mathrm{B2} \mathrm{cm}$ and $P 2 \mathrm{~cm}$. Further examination of the diffraction data allowed us to eliminate the $B b 2_{1} m$ structural models on the basis of extinction conditions, as described in Figure S1 in Supporting Information, to leave 3 candidate structures.

Structural models were constructed for $\mathrm{LiNdNb}_{2} \mathrm{O}_{7}$ and $\mathrm{LiNdTa}_{2} \mathrm{O}_{7}$ in space groups $P 2_{1} \mathrm{~nm}, \mathrm{~B} 2 \mathrm{~cm}$ and $P 2 \mathrm{~cm}$. The lithium cations reside in 4 -coordinate, pseudo-tetrahedral sites located between the perovskite double-layers of the phase. As there are twice as many of these sites in the aristotype structure than are required to satisfy the $\mathrm{LiNdM}_{2} \mathrm{O}_{7}$ stoichiometry, it is possible to arrange the lithium cations in either ordered or disordered configurations. The structural model in space group $P 2{ }_{1} n m$ locates the lithium coordination positions on two separate $4 b$ crystallographic sites. The model in space group $P 2 \mathrm{~cm}$ has two $2 a$ and two $2 b$ sites while in space group $B 2 \mathrm{~cm}$ there is one $4 a$ and one $4 b$ site to describe the 4-coordinate lithium sites. As a result the lithium cations can adopt a variety of ordered or disordered arrangements in these models.

Refinement of the three remaining candidate models against the neutron powder diffraction data proceeded smoothly for both phases. During the refinements all atomic positional and displacement parameters were refined freely and the occupancies of the lithium sites were also refined (within the constraint of the overall sample stoichiometry) to determine if the lithium cations were ordered or disordered. It was observed that ordered lithium configurations gave superior fits for both the $P 2 \mathrm{~cm}$ and $B 2 \mathrm{~cm}$ models while in the $P 2{ }_{1} \mathrm{~nm}$ model with a disordered lithium configuration gave a better fit than an ordered configuration.

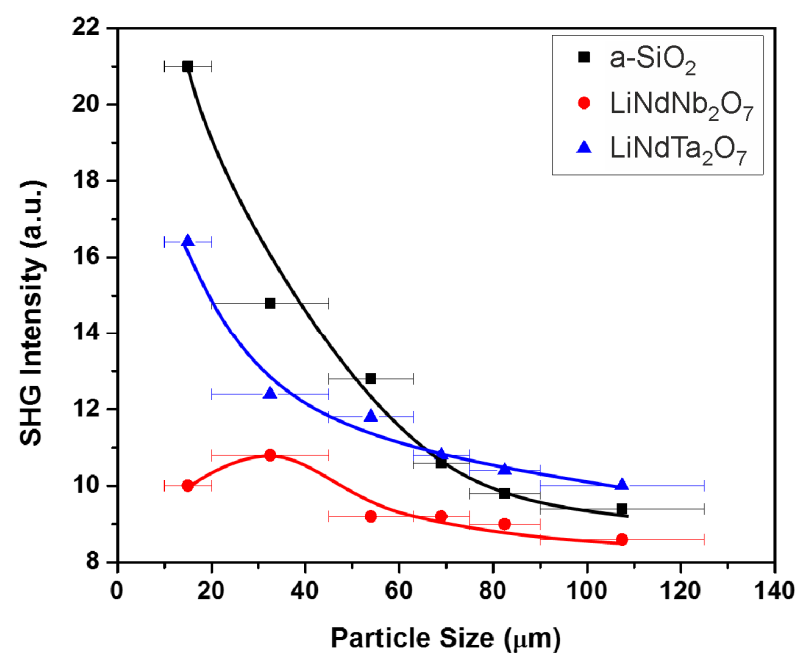

Figure 2. Plot of SHG activity of $\mathrm{LiNdNb}_{2} \mathrm{O}_{7}$ and $\mathrm{LiNdTa}_{2} \mathrm{O}_{7}$ as a function of particle size, compared to that of an $\alpha-\mathrm{SiO}_{2}$ standard.

Fitting statistics for the three structural models reveal that for both $\mathrm{LiNdNb}_{2} \mathrm{O}_{7}$ and $\mathrm{LiNdTa}_{2} \mathrm{O}_{7}$ the $P 2 \mathrm{~cm}$ and $B 2 \mathrm{~cm}$ models give far superior fits to the data than the lithium-disordered $P 2_{1} n m$ model (Table 1), however the difference between the quality of the fits for the 'unconstrained $P 2 \mathrm{~cm}$ ' and $B 2 \mathrm{~cm}$ models is too small to pick a 'correct' structural solution.

Close examination of the refined structures from 'unconstrained' $P 2 \mathrm{~cm}$ models reveals they are very irregular. The $P 2 \mathrm{~cm}$ model has $2 \mathrm{Li}, 2 \mathrm{Nd}, 2 \mathrm{Nb} / \mathrm{Ta}$ and 8 oxide ions in the asymmetric unit - twice as many as the $B 2 \mathrm{~cm}$ model. This lower symmetry allows the model to yield a structure in which chemically equivalent atoms reside in different local environments. As a result bond valence sums (BVS) ${ }^{55-56}$ calculated for the pairs of chemically equivalent cations (listed in Table $\mathrm{S} 2$, in the Supporting Information) are very uneven for the 'unconstrained $P 2 \mathrm{~cm}$ ' model, breaking the chemical plausibility criterion described above. To address this situation, we added constraints to the $P 2 \mathrm{~cm}$ model to make the pairs of cation sites more equivalent. This more symmetric model (labelled $P 2 \mathrm{~cm}_{\text {(constrained) }}$ ) fitted the data much more poorly than the $B 2 \mathrm{~cm}$ model, as shown in Table 1, indicating that the $a^{-} b^{-} c^{+} /-\left(a^{-} b^{-}\right) c^{+}$distortion of the $P 2 \mathrm{~cm}$ model is incorrect and 


\begin{tabular}{|c|c|c|c|c|c|}
\hline Atom & site & $x$ & $y$ & $z$ & $\mathrm{U}_{\text {iso }}\left(\AA^{3}\right)$ \\
\hline $\operatorname{Li}(1)$ & $4 a$ & $\begin{array}{l}0.5820(20) \\
0.56127\end{array}$ & $\begin{array}{l}0 \\
0\end{array}$ & $\begin{array}{l}1 / 2 \\
1 / 2\end{array}$ & $0.0294(22)$ \\
\hline $\mathrm{Nd}(1)$ & $4 c$ & $\begin{array}{l}0.2957(8) \\
0.28281\end{array}$ & $\begin{array}{l}0.2520(5) \\
0.24873\end{array}$ & $\begin{array}{l}1 / 4 \\
1 / 4\end{array}$ & $0.0161(6)$ \\
\hline $\mathrm{Nb}(1)$ & $8 d$ & $\begin{array}{l}0.3136(7) \\
0.31942 \\
\end{array}$ & $\begin{array}{l}0.7518(4) \\
0.75086 \\
\end{array}$ & $\begin{array}{l}0.1390(1) \\
0.13948 \\
\end{array}$ & $0.0162(4)$ \\
\hline $\mathrm{O}(1)$ & $8 d$ & $\begin{array}{l}0.3101(8) \\
0.31082\end{array}$ & $\begin{array}{l}0.8386(3) \\
0.84089 \\
\end{array}$ & $\begin{array}{l}0.0566(1) \\
0.05598\end{array}$ & $0.0172(5)$ \\
\hline $\mathrm{O}(2)$ & $8 d$ & $\begin{array}{l}0.1225(5) \\
0.12826\end{array}$ & $\begin{array}{l}0.4556(5) \\
0.44969\end{array}$ & $\begin{array}{l}0.1443(1) \\
0.14445\end{array}$ & $0.0216(6)$ \\
\hline $\mathrm{O}(3)$ & $8 d$ & $\begin{array}{l}0.5598(6) \\
0.55002\end{array}$ & $\begin{array}{l}0.0154(7) \\
0.03124\end{array}$ & $\begin{array}{l}0.1719(1) \\
0.17302\end{array}$ & $0.0227(6)$ \\
\hline $\mathrm{O}(4)$ & $4 c$ & $\begin{array}{l}0.3195(10) \\
0.34469\end{array}$ & $\begin{array}{l}0.6819(5) \\
0.67719\end{array}$ & $\begin{array}{l}1 / 4 \\
1 / 4\end{array}$ & $0.0201(8)$ \\
\hline \multicolumn{6}{|c|}{$\begin{array}{l}\mathrm{LiNdNb}_{2} \mathrm{O}_{7}-\text { space group } B 2 c m(\# 39) \\
\text { Lattice parameters from experiment: } \\
a=5.4498(2) \AA, b=5.3974(2) \AA, c=20.4556(8) \AA \text {, } \\
\text { volume }=601.70(7) \AA^{3} \\
\text { Lattice parameters from theory: } \\
a=5.43799 \AA, b=5.37584 \AA, c=20.47048 \AA, \\
\text { volume }=598.43 \AA^{3} \\
\text { Formula weight: } 448.99 \mathrm{~g} \mathrm{~mol}^{-1}, \mathrm{Z}=4 \\
\text { Radiation source: Neutron Time of flight } \\
\text { Temperature: } 298 \mathrm{~K} \\
\chi^{2}=12.78, w \mathrm{Rp}=5.49 \%, \mathrm{Rp}=6.04 \%\end{array}$} \\
\hline
\end{tabular}

Table 2. Parameters from the structural refinement of $\mathrm{LiNdNb}_{2} \mathrm{O}_{7}$ against neutron powder diffraction data collected at $298 \mathrm{~K}$ compared to structural data from our first-principles calculations. For each atomic species, the first row of fractional coordinates corresponds to experimental data (with the corresponding isotropic displacement parameter), whereas the second row (italic) is from our DFT calculations.

that $\mathrm{LiNdNb}_{2} \mathrm{O}_{7}$ and $\mathrm{LiNdTa}_{2} \mathrm{O}_{7}$ adopt $a^{-} a^{-} c^{+} /-\left(a^{-} a^{-} c^{+}\right)$distorted, $B 2 \mathrm{~cm}$ symmetry Ruddlesden-Popper structures. Our DFT calculations confirm that a structure with $B 2 \mathrm{~cm}$ symmetry is more stable than $P 2 \mathrm{~cm}$, however the energy difference between the phases is very small (less than $0.05 \mathrm{meV} /$ formula unit). Indeed, the $P 2 \mathrm{~cm}$ model essentially relaxes to the $B 2 \mathrm{~cm}$ structure.

Observed, calculated and difference plots from the refinement of $B 2 \mathrm{~cm}$ symmetry models of $\mathrm{LiNdNb}_{2} \mathrm{O}_{7}$ and $\mathrm{LiNdTa}_{2} \mathrm{O}_{7}$ against neutron powder diffraction data are shown in Figures $\mathrm{S} 2$ and $\mathrm{S} 3$ respectively. Complete descriptions of the refined structures of $\mathrm{LiNdNb}_{2} \mathrm{O}_{7}$ and $\mathrm{LiNdTa}_{2} \mathrm{O}_{7}$ are detailed in Tables 2 and 3 respectively, with selected bond lengths in Table 4 . Tables 2 and 3 also show that our relaxed computational structures are in excellent agreement with the experimentally refined structures.

Since these Li phases are polar they will exhibit a macroscopic polarization, which if switchable, would make these materials ferroelectric. It is usually reasonably straightforward to calculate the polarization from first principles but this is not the case here. This is because we require a reference paraelectric structure to calculate the polarization, in addition to the polar, distorted structure (we calculate the change in polarization upon application of an electric field, and not the polarization itself, since this quantity is ill-defined in a solid). The choice of reference paraelectric structure is not immediately obvious. We could propose a structure with $\mathrm{Bmcm}$ symmetry (for example) as our paraelectric reference structure, since this space group is connected to $B 2 \mathrm{~cm}$ by a

\begin{tabular}{|c|c|c|c|c|c|}
\hline Atom & site & $x$ & $y$ & $z$ & $\mathrm{U}_{\text {iso }}\left(\AA^{3}\right)$ \\
\hline $\operatorname{Li}(1)$ & $4 a$ & $\begin{array}{l}0.5782(16) \\
0.56132\end{array}$ & $\begin{array}{l}0 \\
0 \\
\end{array}$ & $\begin{array}{l}0 \\
0\end{array}$ & $0.0235(15)$ \\
\hline $\mathrm{Nd}(1)$ & $4 c$ & $\begin{array}{l}0.2994(7) \\
0.28495\end{array}$ & $\begin{array}{l}0.2547(4) \\
0.25071\end{array}$ & $\begin{array}{l}1 / 4 \\
1 / 4\end{array}$ & $0.0132(4)$ \\
\hline $\mathrm{Ta}(1)$ & $8 d$ & $\begin{array}{l}0.3178(6) \\
0.32224 \\
\end{array}$ & $\begin{array}{l}0.7540(3) \\
0.75242 \\
\end{array}$ & $\begin{array}{l}0.1397(1) \\
0.13989 \\
\end{array}$ & $0.0108(3)$ \\
\hline $\mathrm{O}(1)$ & $8 d$ & $\begin{array}{l}0.3115(7) \\
0.31069 \\
\end{array}$ & $\begin{array}{l}0.8374(2) \\
0.84079 \\
\end{array}$ & $\begin{array}{l}0.0564(1) \\
0.05575 \\
\end{array}$ & $0.0158(4)$ \\
\hline $\mathrm{O}(2)$ & $8 d$ & $\begin{array}{l}0.1170(4) \\
0.12507 \\
\end{array}$ & $\begin{array}{l}0.4611(4) \\
0.45247 \\
\end{array}$ & $\begin{array}{l}0.1457(1) \\
0.14523\end{array}$ & $0.0195(5)$ \\
\hline $\mathrm{O}(3)$ & $8 d$ & $\begin{array}{l}0.5563(5) \\
0.55012\end{array}$ & $\begin{array}{l}0.0182(5) \\
0.02957\end{array}$ & $\begin{array}{l}0.1721(1) \\
0.17341\end{array}$ & $0.0155(4)$ \\
\hline $\mathrm{O}(4)$ & $4 c$ & $\begin{array}{l}0.3232(8) \\
0.34333\end{array}$ & $\begin{array}{l}0.6833(3) \\
0.67899\end{array}$ & $\begin{array}{l}1 / 4 \\
1 / 4\end{array}$ & $0.0174(6)$ \\
\hline $\begin{array}{l}\text { LiNdT } \\
\text { Lattice } \\
a= \\
\text { volum } \\
\text { Lattice } \\
a= \\
\text { volum } \\
\text { Formu } \\
\text { Radiat } \\
\text { Tempe } \\
\chi^{2}=5 .\end{array}$ & $\begin{array}{l}4427 \\
=603 \\
\text { aram } \\
441 \\
=60 \\
\text { weis } \\
\text { n sou } \\
\text { ature: } \\
5, \text { wR }\end{array}$ & 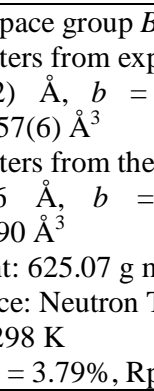 & $\begin{array}{l}c m(\# 39) \\
\text { eriment: } \\
5.4092(2) \\
\text { ry: } \\
5.38892 \\
\text { ol }^{-1}, \mathrm{Z}=4 \\
\text { ime of flight } \\
=4.38 \%\end{array}$ & $\begin{array}{l}c=2 \\
, c=\end{array}$ & $\begin{array}{l}5011(7) \AA ⿻ \\
.52571 \AA,\end{array}$ \\
\hline
\end{tabular}

Table 3. Parameters from the structural refinement of $\mathrm{LiNdTa}_{2} \mathrm{O}_{7}$ against neutron powder diffraction data collected at $298 \mathrm{~K}$ compared to structural data from our first-principles calculations. For each atomic species, the first row of fractional coordinates corresponds to experimental data (with the corresponding isotropic displacement parameter), whereas the second row (italic) is from our DFT calculations.

\begin{tabular}{|c|c|c|c|c|c|}
\hline \multirow[t]{2}{*}{ Cation } & \multirow[t]{2}{*}{ Anion } & \multicolumn{2}{|c|}{$\mathrm{LiNdNb}_{2} \mathrm{O}_{7}$} & \multicolumn{2}{|c|}{$\mathrm{LiNdTa}_{2} \mathrm{O}_{7}$} \\
\hline & & $\begin{array}{l}\text { Length } \\
(\AA ̊)\end{array}$ & BVS & $\begin{array}{l}\text { Length } \\
(\AA)\end{array}$ & BVS \\
\hline \multirow[t]{2}{*}{$\operatorname{Li}(1)$} & $\mathrm{O}(1) \times 2$ & $1.909(12)$ & \multirow[t]{2}{*}{0.99} & $1.930(7)$ & \multirow[t]{2}{*}{0.98} \\
\hline & $\mathrm{O}(1) \times 2$ & $2.072(13)$ & & $2.054(8)$ & \\
\hline \multirow[t]{8}{*}{$\mathrm{Nd}(1)$} & $\mathrm{O}(2) \times 2$ & $2.602(4)$ & \multirow[t]{8}{*}{3.07} & $2.609(3)$ & \multirow[t]{8}{*}{3.03} \\
\hline & $\mathrm{O}(2) \times 2$ & $3.215(4)$ & & $3.150(4)$ & \\
\hline & $\mathrm{O}(3) \times 2$ & $2.501(5)$ & & $2.479(4)$ & \\
\hline & $\mathrm{O}(3) \times 2$ & $2.507(5)$ & & $2.546(4)$ & \\
\hline & $\mathrm{O}(4)$ & $2.324(4)$ & & $2.322(4)$ & \\
\hline & $\mathrm{O}(4)$ & $2.620(8)$ & & $2.613(7)$ & \\
\hline & $\mathrm{O}(4)$ & $2.877(8)$ & & $2.871(7)$ & \\
\hline & $\mathrm{O}(4)$ & $3.080(4)$ & & $3.094(4)$ & \\
\hline \multirow[t]{6}{*}{$\mathrm{Nb} / \mathrm{Ta}(1)$} & $\mathrm{O}(1)$ & $1.751(3)$ & \multirow[t]{6}{*}{5.09} & $1.767(3)$ & \multirow[t]{6}{*}{5.18} \\
\hline & $\mathrm{O}(2)$ & $1.911(5)$ & & $1.929(4)$ & \\
\hline & $\mathrm{O}(2)$ & $2.025(5)$ & & $2.005(4)$ & \\
\hline & $\mathrm{O}(3)$ & $1.986(6)$ & & $1.996(4)$ & \\
\hline & $\mathrm{O}(3)$ & $2.068(5)$ & & $2.042(4)$ & \\
\hline & $\mathrm{O}(4)$ & $2.302(2)$ & & $2.294(2)$ & \\
\hline
\end{tabular}

Table 4. Selected bond lengths from the structures of $\mathrm{LiNdNb}_{2} \mathrm{O}_{7}$ and $\mathrm{LiNdTa}_{2} \mathrm{O}_{7}$ refined in space group $\mathrm{B} 2 \mathrm{~cm}$. 


\begin{tabular}{|l|l|l|l|l|l|}
\hline space group & tilt system & Glazer tilt & $\chi^{2}$ & wRp (\%) & Rp (\%) \\
\hline $\mathrm{NaNdNb}_{2} \mathrm{O}_{7}$ & $\Phi_{1} \Phi_{2} 0 / \Phi_{2} \Phi_{1} 0$ & $a^{-} b^{-} c^{0} / b^{-} a^{-} c^{0}$ & 8.40 & 4.67 & 4.68 \\
\hline Pnnm \#58 & $\Phi \Phi \Psi_{\mathrm{z}} / \Phi \Phi-\Psi_{\mathrm{z}}$ & $a^{-} a^{-} c^{+} / a^{-} a^{-}-c^{+}$ & 9.97 & 5.08 & 5.20 \\
\hline Pnam \#62 & $a^{-} b^{0} c^{0} / b^{0} a^{-} c^{0}$ & 8.86 & 4.79 & 4.82 \\
\hline P4 ${ }_{2} / m n m \# 136$ & $\Phi 00 / 0 \Phi 0$ & $a^{-} b^{-} c^{+} /-\left(b^{-} a^{-}\right) c^{0}$ & 19.70 & 6.95 & 5.31 \\
\hline $\mathrm{NaNdTa}_{2} \mathrm{O}_{7}$ & $a^{-} a^{-} c^{+} /-\left(a^{-} a^{-}\right) c^{+}$ & 16.85 & 6.42 & 5.09 \\
\hline Pccm \#49 & $\Phi_{1} \Phi_{2} 0 /-\left(\Phi_{2} \Phi_{1}\right) 0$ & $a^{-} b^{-} c^{0} / b^{-} a^{-} c^{0}$ & 6.30 & 3.93 & 3.82 \\
\hline Pbcm \#57 & $\Phi \Phi \Psi_{\mathrm{z}} /-(\Phi \Phi) \Psi_{\mathrm{z}}$ & $a^{-} a^{-} c^{+} / a^{-} a^{-}-c^{+}$ & 5.99 & 3.83 & 3.94 \\
\hline Pnnm \#58 & $\Phi_{1} \Phi_{2} 0 / \Phi_{2} \Phi_{1} 0$ & $a^{-} b^{0} c^{0} / b^{0}-a^{-} c^{0}$ & 21.78 & 7.31 & 5.57 \\
\hline Pnam \#62 & $\Phi \Phi \Psi_{\mathrm{z}} / \Phi \Phi-\Psi_{\mathrm{z}}$ & $a^{-} b^{0} c^{0} / b^{0} a^{-} c^{0}$ & 6.96 & 4.13 & 3.98 \\
\hline P4 $4_{2} / m c m \# 132$ & $\Phi 00 / 0-\Phi 0$ & $\Phi 00 / 0 \Phi 0$ & P4 $/$ /mnm \#136
\end{tabular}

Table 5. Fitting statistics from the structural refinement of $\mathrm{NaNdNb}_{2} \mathrm{O}_{7}$ and $\mathrm{NaNdTa}_{2} \mathrm{O}_{7}$ against neutron powder diffraction data.

single distortion that breaks inversion symmetry and transforms like the irreducible representation $\Gamma_{4}^{--}$. However, if polarization switching actually proceeds through a different structure, then our prediction may be quite poor. Rather than muddy the literature with theoretical results of questionable physical value, we have chosen not to calculate a polarization value in this instance.

Structural Characterization of $\mathrm{NaNdNb}_{2} \mathrm{O}_{7}$ and $\mathrm{NaNdTa}_{2} \mathrm{O}_{7}$. Synchrotron X-ray and neutron powder diffraction data collected from $\mathrm{NaNdNb}_{2} \mathrm{O}_{7}$ and $\mathrm{NaNdTa}_{2} \mathrm{O}_{7}$ could be indexed using a tetragonal unit cells $\left(\mathrm{NaNdNb}_{2} \mathrm{O}_{7}: a \sim b=\right.$ $5.483 \AA, c=20.911 \AA$ 和 $\mathrm{NaNda}_{2} \mathrm{O}_{7}: a \sim b=5.469 \AA, c=$ $21.134 \AA$ ) consistent with distorted $n=2$ Ruddlesden-Popper type structures. Again this contrasts previous reports of an undistorted $(I 4 / \mathrm{mmm})$ structure for $\mathrm{NaNdNb}_{2} \mathrm{O}_{7}{ }^{35}$ We did not observe any evidence by diffraction for mixed cation $(\mathrm{Na} / \mathrm{Rb}) \mathrm{NdNb}_{2} \mathrm{O}_{7}$ or $(\mathrm{Na} / \mathrm{Rb}) \mathrm{NdTa}_{2} \mathrm{O}_{7}$ phases during the cation exchange reactions, with $\mathrm{RbNdM}_{2} \mathrm{O}_{7}$ starting materials converting directly to $\mathrm{NaNdM}_{2} \mathrm{O}_{7}$ product phases.

SHG measurements revealed that neither $\mathrm{NaNdNb}_{2} \mathrm{O}_{7}$ or $\mathrm{NaNdTa}_{2} \mathrm{O}_{7}$ are $\mathrm{SHG}$ active, indicating that both phases adopt centrosymmetric crystal structures. Given that it is possible for phases to be metrically tetragonal but described in an orthorhombic space group, our symmetry analysis (Table S1) indicates there are 12 possible centrosymmetric tetragonal or orthorhombic models for the $\mathrm{NaNdM}_{2} \mathrm{O}_{7}$ phases: $P 4_{2} / \mathrm{mcm}$, $P 4_{2} / m n m$, Pccm, Pbcb, Pbcm, Pnnm, Pnab, Pnam, Bbmm, $B b c m, B m c m$ and $B b c b$. Again these are described with the stacking axis aligned along $z$.

Synchrotron X-ray diffraction data allow us to eliminate all the centered models on the basis of extinction conditions as shown in Figure S4. Further examination of the diffraction data show that the $\mathrm{P}_{2} / \mathrm{mcm}, \mathrm{Pccm}$ and $\mathrm{Pbcm}$ structural models can be eliminated for $\mathrm{NaNdNb}_{2} \mathrm{O}_{7}$, and the $P b c b$ and $P n a b$ models can be eliminated for both $\mathrm{NaNdNb}_{2} \mathrm{O}_{7}$ and $\mathrm{NaNdTa}_{2} \mathrm{O}_{7}$, which leaves only 3 candidate structural models for the $\mathrm{NaNdNb}_{2} \mathrm{O}_{7}\left(\mathrm{P}_{2} / \mathrm{mnm}\right.$, Pnnm and Pnam $)$ and 6 candidate structural models for the $\mathrm{NaNdTa}_{2} \mathrm{O}_{7}\left(P 4_{2} / \mathrm{mcm}\right.$, $\mathrm{P}_{2} /$ mnm, Pccm, Pbcm, Pnnm, and Pnam).

In a direct analogy to the lithium phases, the sodium cations reside within 4-coordinate, pseudo-tetrahedral sites located between the perovskite double-layers, and can also adopt ordered or disordered configurations. In the structural model in space Pnam, the sodium cations reside on an $8 d$ site which must be half-occupied to respect the sample stoichiometry, and as a result the sodium cations are in a disordered configuration. In contrast, the model in space group $P 4_{2} / \mathrm{mcm}$ has one $4 e$, one $2 b$ and one $2 d$ sodium site; $P 4_{2} / \mathrm{mnm}$ has one $4 d$ and one $4 e$ sodium site; $P c c m$ has one $2 e$, one $2 f$, one $2 g$ and one $2 h$ sodium site; $P b c m$ has two separate $4 c$ sodium sites, and Pnnm has one $4 e$ and one $4 f$ sodium site allowing the sodium cations to adopt a range of ordered and disordered configurations in these five models.

Structural models were constructed in all the remaining candidate space groups and refined against the neutron powder diffraction data. During the refinements all atomic positional and displacement parameters were refined freely. The occupancies of the sodium sites were refined (within the constraint of the overall sample stoichiometry) to determine if the sodium cations were ordered or disordered, and it was observed that ordered sodium configurations gave superior fits for the $\mathrm{P}_{2} / \mathrm{mnm}$ and Pnnm models, while disordered sodium configurations gave superior fits for both the $P 4_{2} / \mathrm{mcm}, P c c m$ and Pbcm models. $\mathrm{NdNbO}_{4}$ was added as a second phase for the refinement of $\mathrm{NaNdNb}_{2} \mathrm{O}_{7}$.

Refinement of all models against the neutron powder diffraction data proceeded smoothly. Fitting statistics (Table 5) show that the models in space groups Pnnm, Pnam and $P 4_{2} / m n m$ achieve the best fits to the data for both $\mathrm{NaNdNb}_{2} \mathrm{O}_{7}$ and $\mathrm{NaNdTa}_{2} \mathrm{O}_{7}$. However close inspection of the fits using the Pnam models reveal these do not account for the intensity of the [114] and [112] diffraction peaks at $3.12 \AA$ and $3.63 \AA$ respectively, as shown in Figures S5 and S6 in the Supporting Information, indicating this model is incorrect.

The remaining two models $P 4_{2} / m n m\left(a^{-} b^{0} c^{0} / b^{0} a^{-} c^{0}\right)$ and Pnnm $\left(a^{-} b^{-} c^{0} / b^{-} a^{-} c^{0}\right)$ describe similar octahedral tilting patterns, with the $P 4_{2} / \mathrm{mnm}$ describing a special case of the Pnnm model in which the ' $b$ ' tilt has zero magnitude. Close inspection of the atomic coordinates of the Pnnm models refined for $\mathrm{NaNdNb}_{2} \mathrm{O}_{7}$ and $\mathrm{NaNdTa}_{2} \mathrm{O}_{7}$ reveal O-O-O bond angles corresponding to ' $a$ ' and ' $b$ ' tilts are very different, and the magnitude of the ' $b$ ' tilt is very close to zero, as shown in detail in Figure S7 in the supporting information. Given the similarity of the fitting statistics of the $P 4_{2} / \mathrm{mnm}$ and Pnnm models and the small magnitude of the ' $b$ ' tilt it is hard to differentiate between these two models on the basis of diffraction data alone. 


\begin{tabular}{|c|c|c|c|c|c|}
\hline Atom & site & $x$ & $y$ & $z$ & $\mathrm{U}_{\text {iso }}\left(\AA^{3}\right)$ \\
\hline $\mathrm{Na}(1)$ & $4 e$ & $\begin{array}{l}0 \\
0\end{array}$ & $\begin{array}{l}0 \\
0\end{array}$ & $\begin{array}{l}0.2649(3) \\
0.26413\end{array}$ & $0.0346(17)$ \\
\hline $\mathrm{Nd}(1)$ & $4 f$ & $\begin{array}{l}0.2587(3) \\
0.26241\end{array}$ & $\begin{array}{l}0.2587(3) \\
0.26241\end{array}$ & $\begin{array}{l}0 \\
0\end{array}$ & $0.0049(4)$ \\
\hline $\mathrm{Nb}(1)$ & $8 j$ & $\begin{array}{l}0.2531(3) \\
0.25345 \\
\end{array}$ & $\begin{array}{l}0.2531(3) \\
0.25345 \\
\end{array}$ & $\begin{array}{l}0.3943(0) \\
0.39445 \\
\end{array}$ & $0.0030(3)$ \\
\hline $\mathrm{O}(1)$ & $4 g$ & $\begin{array}{l}0.8034(4) \\
0.80966\end{array}$ & $\begin{array}{l}0.8034(4) \\
0.80966\end{array}$ & $\begin{array}{l}1 / 2 \\
1 / 2 \\
\end{array}$ & $0.0182(10)$ \\
\hline $\mathrm{O}(2)$ & $4 e$ & $\begin{array}{l}1 / 2 \\
1 / 2\end{array}$ & $\begin{array}{l}1 / 2 \\
1 / 2\end{array}$ & $\begin{array}{l}0.5725(1) \\
0.57197\end{array}$ & $0.0029(8)$ \\
\hline $\mathrm{O}(3)$ & $4 e$ & $\begin{array}{l}0 \\
0\end{array}$ & $\begin{array}{l}0 \\
0\end{array}$ & $\begin{array}{l}0.6071(2) \\
0.60810\end{array}$ & $0.0252(12)$ \\
\hline $\mathrm{O}(4)$ & $8 h$ & $\begin{array}{l}1 / 2 \\
1 / 2\end{array}$ & $\begin{array}{l}0 \\
0\end{array}$ & $\begin{array}{l}0.4153(1) \\
0.41723\end{array}$ & $0.0218(7)$ \\
\hline $\mathrm{O}(5)$ & $8 j$ & $\begin{array}{l}0.7138(2) \\
0.71507\end{array}$ & $\begin{array}{l}0.7138(2) \\
0.71507\end{array}$ & $\begin{array}{l}0.6885(1) \\
0.68983\end{array}$ & $0.0122(5)$ \\
\hline $\begin{array}{l}\text { NaNd } \\
\text { Lattice } \\
a= \\
\text { volum } \\
\text { Lattice } \\
a= \\
\text { volum } \\
\text { Formu } \\
\text { Radiat } \\
\text { Temp } \\
\chi^{2}=8 .\end{array}$ & $\begin{array}{l}4829 \\
=628 \\
\text { paran } \\
=68 \\
=62 \\
\text { wei } \\
\text { on sou } \\
\text { ature }\end{array}$ & 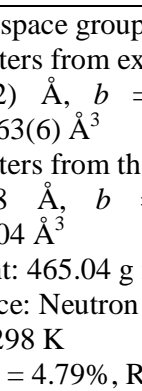 & $\begin{array}{l}4_{2} / m n m \text { (\# } \\
\text { eriment: } \\
5.4829(2) \\
\text { rry: } \\
5.48088 \\
\text { lol }^{-1}, \mathrm{Z}=4 \\
\text { ime of fligh } \\
=4.82 \%\end{array}$ & $\begin{array}{l}\text { 36) } \\
\AA, \quad c=2 \\
\AA, \quad c=\end{array}$ & $\begin{array}{l}9112(8) \AA, \\
0.80676 \AA,\end{array}$ \\
\hline
\end{tabular}

Table 6. Parameters from the structural refinement of $\mathrm{NaNdNb}_{2} \mathrm{O}_{7}$ against neutron powder diffraction data collected at $298 \mathrm{~K}$ compared to structural data from our first-principles calculations. For each atomic species, the first row of fractional coordinates corresponds to experimental data (with the corresponding isotropic displacement parameter), whereas the second row (italic) is from our DFT calculations.

DFT calculations confirm that $P 4_{2} / m n m$ is more stable than Pnnm. The energy difference between the two phases in the case of $\mathrm{NaNdNb}_{2} \mathrm{O}_{7}$ is less than $0.05 \mathrm{meV} /$ formula unit, suggesting that the two structures are likely identical within the calculation precision. This is confirmed by close inspection of the relaxed structures, revealing that the optimized Pnnm model has essentially zero $b$ tilt, consistent with $P 4_{2} / \mathrm{mnm}$ symmetry. This also happens for $\mathrm{NaNdTa}_{2} \mathrm{O}_{7}$, however the Pnnm structure ends up more stable than $P 4_{2} / m n m$ by less than $1 \mathrm{meV} /$ formula unit. Given the tiny energy difference between the two structures and the fact that the Pnnm model relaxes to $P 4_{2} / m n m$, we conclude that the best and simplest description of the structures of $\mathrm{NaNdNb}_{2} \mathrm{O}_{7}$ and $\mathrm{NaNdTa}_{2} \mathrm{O}_{7}$ are given by the $P 4_{2} / m n m$ models.

Observed calculated and difference plots from the refinement of $\mathrm{P}_{2} / \mathrm{mnm}$ symmetry models against neutron powder diffraction data are shown in Figures S8 and S9. Complete descriptions of the refined structures of $\mathrm{NaNdNb}_{2} \mathrm{O}_{7}$ and $\mathrm{NaNdTa}_{2} \mathrm{O}_{7}$ detailed in Tables 6 and 7 respectively, with selected bond lengths in Table 8. Parameters from the relaxed computational structures of $\mathrm{NaNdNb}_{2} \mathrm{O}_{7}$ and $\mathrm{NaNdTa}_{2} \mathrm{O}_{7}$ are shown in Tables 6 and 7, again showing excellent agreement with the experimentally determined structures.

\begin{tabular}{|c|c|c|c|c|c|}
\hline Atom & site & $x$ & $y$ & $z$ & $\mathrm{U}_{\text {iso }}\left(\AA^{3}\right)$ \\
\hline $\mathrm{Na}(1)$ & $4 e$ & $\begin{array}{l}0 \\
0\end{array}$ & $\begin{array}{l}0 \\
0\end{array}$ & $\begin{array}{l}0.2608(4) \\
0.26205\end{array}$ & $0.0427(17)$ \\
\hline $\mathrm{Nd}(1)$ & $4 f$ & $\begin{array}{l}0.2569(3) \\
0.26326\end{array}$ & $\begin{array}{l}0.2569(3) \\
0.26326\end{array}$ & $\begin{array}{l}0 \\
0\end{array}$ & $0.0043(4)$ \\
\hline $\mathrm{Ta}(1)$ & $8 j$ & $\begin{array}{l}0.2543(3) \\
0.25327 \\
\end{array}$ & $\begin{array}{l}0.2543(3) \\
0.25327 \\
\end{array}$ & $\begin{array}{l}0.3957(1) \\
0.39503 \\
\end{array}$ & $0.0050(3)$ \\
\hline $\mathrm{O}(1)$ & $4 g$ & $\begin{array}{l}0.8009(4) \\
0.80697\end{array}$ & $\begin{array}{l}0.8009(4) \\
0.80697\end{array}$ & $\begin{array}{l}1 / 2 \\
1 / 2 \\
\end{array}$ & $0.0130(9)$ \\
\hline $\mathrm{O}(2)$ & $4 e$ & $\begin{array}{l}1 / 2 \\
1 / 2 \\
\end{array}$ & $\begin{array}{l}1 / 2 \\
1 / 2 \\
\end{array}$ & $\begin{array}{l}0.5742(2) \\
0.57203\end{array}$ & $0.0101(9)$ \\
\hline $\mathrm{O}(3)$ & $4 e$ & $\begin{array}{l}0 \\
0\end{array}$ & $\begin{array}{l}0 \\
0\end{array}$ & $\begin{array}{l}0.6020(2) \\
0.60541\end{array}$ & $0.0352(15)$ \\
\hline $\mathrm{O}(4)$ & $8 h$ & & $\begin{array}{l}0 \\
0\end{array}$ & $\begin{array}{l}0.4160(1) \\
0.41761\end{array}$ & $0.0216(7)$ \\
\hline $\mathrm{O}(5)$ & $8 j$ & $\begin{array}{l}0.7181(3) \\
0.71783\end{array}$ & $\begin{array}{l}0.7181(3) \\
0.71783\end{array}$ & $\begin{array}{l}0.6883(1) \\
0.68968\end{array}$ & $0.0099(5)$ \\
\hline \multicolumn{6}{|c|}{$\begin{array}{l}\mathrm{NaNdTa}_{2} \mathrm{O}_{7}-\text { space group } P 4_{2} / m n m(\# 136) \\
\text { Lattice parameters from experiment: } \\
a=5.4686(2) \AA, b=5.4686(2) \AA, c=21.1345(9) \AA \text {, } \\
\text { volume }=632.03(7) \AA^{3} \\
\text { Lattice parameters from theory: } \\
a=5.48525 \AA, \quad b=5.48525 \AA, \quad c=20.94628 \AA \text {, } \\
\text { volume }=630.23 \AA^{3} \\
\text { Formula weight: } 641.12 \mathrm{~g} \mathrm{~mol}^{-1}, \mathrm{Z}=4 \\
\text { Radiation source: Neutron Time of flight } \\
\text { Temperature: } 298 \mathrm{~K} \\
\chi^{2}=6.96, \mathrm{wRp}=4.13 \%, \mathrm{Rp}=3.98 \%\end{array}$} \\
\hline
\end{tabular}

Table 7. Parameters from the structural refinement of $\mathrm{NaNdTa}_{2} \mathrm{O}_{7}$ against neutron powder diffraction data collected at $298 \mathrm{~K}$ compared to structural data from our first-principles calculations. For each atomic species, the first row of fractional coordinates corresponds to experimental data (with the corresponding isotropic displacement parameter), whereas the second row (italic) is from our DFT calculations.

\begin{tabular}{|c|c|c|c|c|c|}
\hline \multirow[b]{2}{*}{ Cation } & \multirow[b]{2}{*}{ Anion } & \multicolumn{2}{|c|}{$\mathrm{NaNdNb}_{2} \mathrm{O}_{7}$} & \multicolumn{2}{|c|}{$\mathrm{NaNdTa}_{2} \mathrm{O}_{7}$} \\
\hline & & $\begin{array}{l}\text { Length } \\
(\AA)\end{array}$ & BVS & $\begin{array}{l}\text { Length } \\
(\AA)\end{array}$ & BVS \\
\hline \multirow{2}{*}{$\mathrm{Na}(1)$} & $\mathrm{O}(5) \times 2$ & $2.303(5)$ & \multirow{2}{*}{0.88} & $2.279(6)$ & \multirow{2}{*}{0.91} \\
\hline & $\mathrm{O}(5) \times 2$ & $2.424(4)$ & & $2.431(5)$ & \\
\hline \multirow{5}{*}{$\mathrm{Nd}(1)$} & $\mathrm{O}(1) \times 2$ & $2.413(4)$ & \multirow{5}{*}{2.96} & $2.430(3)$ & \multirow{5}{*}{2.95} \\
\hline & $\mathrm{O}(1) \times 2$ & $3.092(4)$ & & $3.060(3)$ & \\
\hline & $\mathrm{O}(2) \times 2$ & $2.514(3)$ & & $2.531(3)$ & \\
\hline & $\mathrm{O}(3) \times 2$ & $2.918(4)$ & & $2.860(5)$ & \\
\hline & $\mathrm{O}(4) \times 4$ & $2.627(3)$ & & $2.625(3)$ & \\
\hline \multirow{5}{*}{$\mathrm{Nb} / \mathrm{Ta}(1)$} & $\mathrm{O}(1)$ & $2.253(1)$ & \multirow{5}{*}{5.15} & $2.245(1)$ & \multirow{5}{*}{5.21} \\
\hline & $\mathrm{O}(2)$ & $2.036(2)$ & & $2.004(3)$ & \\
\hline & $\mathrm{O}(3)$ & $1.963(2)$ & & $1.967(2)$ & \\
\hline & $\mathrm{O}(4) \times 2$ & $1.988(2)$ & & $1.981(2)$ & \\
\hline & $\mathrm{O}(5)$ & $1.750(2)$ & & $1.788(2)$ & \\
\hline
\end{tabular}

Table 8. Selected bond lengths from the structures of $\mathrm{NaNdNb}_{2} \mathrm{O}_{7}$ and $\mathrm{NaNdTa}_{2} \mathrm{O}_{7}$ refined in space group $P 4_{2} / \mathrm{mnm}$. 

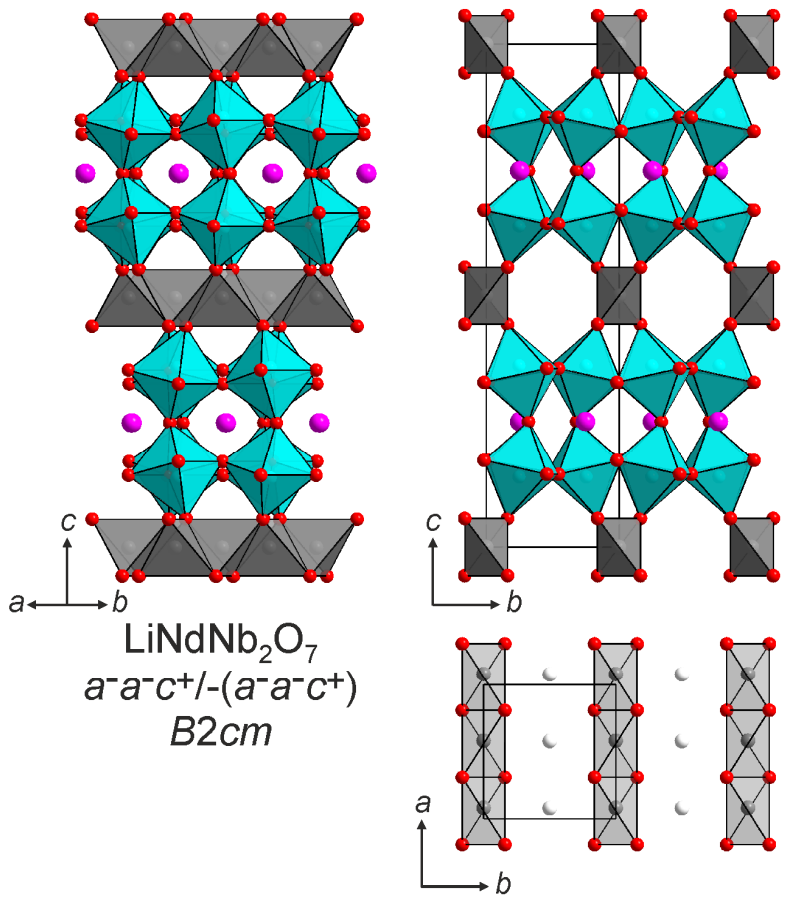
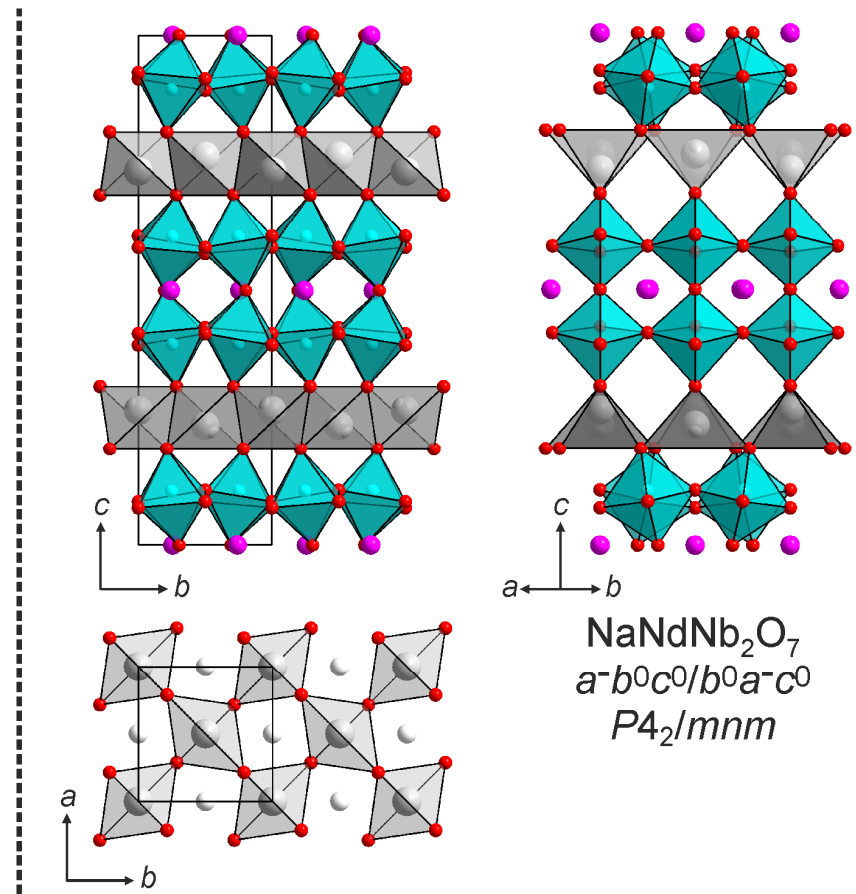

$\mathrm{NaNdNb}_{2} \mathrm{O}_{7}$ $a^{-} b^{0} c^{0} / b^{0} a^{-} c^{0}$ $\mathrm{P}_{2} / \mathrm{mnm}$

Figure 3. The structures of $\mathrm{LiNdNb}_{2} \mathrm{O}_{7}$ (left) and $\mathrm{NaNdNb}_{2} \mathrm{O}_{7}$ (right). Purple, blue, red, dark-grey and light-grey spheres represent $\mathrm{Nd}, \mathrm{Nb}$, $\mathrm{O}, \mathrm{Li}$ and $\mathrm{Na}$ respectively. White spheres indicate the positions of empty $\mathrm{A}^{\prime} \mathrm{O}_{4}$ sites.

\section{Discussion}

The crystal structures of $\mathrm{LiNdM}_{2} \mathrm{O}_{7}$ and $\mathrm{NaNdM}_{2} \mathrm{O}_{7}(\mathrm{M}=$ $\mathrm{Nb}, \mathrm{Ta})$ differ in two key respects: i) the tilting distortion of the $\mathrm{MO}_{6}$ network and ii) the ordering of the $\mathrm{Li}$ and $\mathrm{Na}$ cations within the inter-layer tetrahedral coordination sites.

Considering the tilting distortions first, as noted above, the collective rotations of the connected $\mathrm{MO}_{6}$ octahedra in perovskite lattices occur in response to a size mismatch between the average $\mathrm{B}-\mathrm{O}$ bond lengths $(\mathrm{B}=\mathrm{Nb}, \mathrm{Ta})$ and the $\mathrm{A}-\mathrm{O}$ and $\mathrm{A}^{\prime}-\mathrm{O}$ lengths $\left(A=\mathrm{Nb}, \mathrm{Ta} ; \mathrm{A}^{\prime}=\mathrm{Li}, \mathrm{Na}\right)$ as these low-energy structural deformations allow the A-O and A'-O lengths to contract without changing the B-O length. The magnitude of the cation size mismatch can be conveniently parameterized in the case of the 12-coordinate A-cations using the Goldschmidt tolerance factor, $t=<\mathrm{A}-\mathrm{O}>/(\sqrt{2}<\mathrm{B}-\mathrm{O}>) .{ }^{57}$ Using tabulated ionic radii $\left(\mathrm{Nd}^{3+}=1.27 \AA ; \mathrm{Nb}^{5+}=0.64 \AA ; \mathrm{O}=1.40 \AA\right)^{58}$ a value of $t=0.925$ can be determined for the $\mathrm{NdNb}_{2} \mathrm{O}_{7}$ perovskite sheets, indicating this double-layer will have a strong geometric drive to adopt a significantly distorted configuration in the absence of any influence from the A'-cations. It should also be noted that the 6-coordinate ionic radius of $\mathrm{Ta}^{5+}$ is also $0.64 \AA$, thus it is no surprise that the corresponding niobium and tantalum phases are isostructural.

It is also possible to formulate a tolerance factor, $t^{\prime}$, for the A' tetrahedral cation sites, by considering the $\langle\mathrm{B}-\mathrm{O}\rangle$ and $\left\langle\mathrm{A}^{\prime}-\mathrm{O}\right\rangle$ bond lengths of the undistorted aristotype framework, as described in detail in the supporting information (Figure S10), as $t^{\prime}=<\mathrm{A}^{\prime}-\mathrm{O}>/[(\sqrt{3} / \sqrt{2})<\mathrm{B}-\mathrm{O}>]$. Utilizing the tabulated 4coordinate ionic radii of $\mathrm{Li}^{+}(0.59 \AA)$ and $\mathrm{Na}^{+}(0.99 \AA)$ we can obtain values of $t^{\prime}=0.796$ and $t^{\prime}=0.956$ for $\mathrm{Li} / \mathrm{Nb}$ and $\mathrm{Na} / \mathrm{Nb}$ respectively. The significantly smaller value of $t^{\prime}$ for the $\mathrm{Li} / \mathrm{Nb}$ combination compared to the $\mathrm{Na} / \mathrm{Nb}$ combination provides a simple explanation for the differing tilting patterns of the $\mathrm{Li}$ and $\mathrm{Na}$ phases, however close inspection of the crystal structures reveals more subtle drivers.
Calculating BVS values for the $\mathrm{Na}^{+}$cations in the refined structures of $\mathrm{NaNdNb}_{2} \mathrm{O}_{7}$ and $\mathrm{NdNdTa}_{2} \mathrm{O}_{7}$ (Table 8) reveals that in both structures the Na cations are 'under bonded' (BVS $\left.\mathrm{Na}_{\mathrm{Nb}}=0.88 ; \mathrm{Na}_{\mathrm{Ta}}=0.91\right)$ indicating that the 4-coordinate $\mathrm{Na}$ sites are larger than ideal. In contrast the BVS values for the $\mathrm{Li}^{+}$cations in $\mathrm{LiNdNb}_{2} \mathrm{O}_{7}$ and $\mathrm{LiNdTa}_{2} \mathrm{O}_{7}$ (Table 4) are close to ideal $\left(\mathrm{BVS} \mathrm{Li}_{\mathrm{Nb}}=0.99 ; \mathrm{Li}_{\mathrm{Ta}}=0.98\right)$. This indicates that the tilting distortions of the lithium containing phases have optimized the size of the $\mathrm{Li}$ coordination sites, while the corresponding distortions of the Na-containing phases have not optimized the Na sites. Why the difference?

Figure 3 shows that the sodium cations order within the inter-layer cations sites to form a network of corner-linked $\mathrm{NaO}_{4}$ tetrahedra. This arrangement minimizes $\mathrm{Na}-\mathrm{Na}$ repulsions in line with Pauling's third crystallographic rule. ${ }^{59}$ However a feature of this arrangement is that it is not possible to contract the average $\mathrm{Na}-\mathrm{O}$ bond length via octahedral tilting as the displacement of an oxide ion to shorten one $\mathrm{Na}-\mathrm{O}$ length necessarily elongates another, and as a result the average $\mathrm{Na}-\mathrm{O}$ distance does not change but the average $\mathrm{O}-\mathrm{O}$ separation declines making large angle tilts unfavourable. The only mechanism which allows a contraction of the average $\mathrm{Na}-\mathrm{O}$ bond length is to shrink the inter-layer separation, but again this also shrinks the average O-O separation so can only occur to a limited extent. Thus it can be seen that the small magnitude of the $\mathrm{MO}_{6}$ tilting distortion observed for the $\mathrm{NaNdM}_{2} \mathrm{O}_{7}$ phases, and thus the under bonding of the Na cations, is a consequence of the Na cation ordering scheme, suggesting that in this instance minimizing Na-Na repulsion is energetically more important than optimizing the size of the A' coordination sites.

These same factors (minimizing A'-A' repulsion $v s$ optimizing the size of the $\mathrm{A}^{\prime}$ coordination site) are also operative in determining the structure of the $\mathrm{LiNdM}_{2} \mathrm{O}_{7}$ phases, however the smaller size of the $\mathrm{Li}^{+}$cation means that a different balance is struck. Figure 3 shows that the lithium cations order within 
the inter-layer cations sites of the $\mathrm{LiNdM}_{2} \mathrm{O}_{7}$ phases to form chains of edge-linked $\mathrm{LiO}_{4}$ tetrahedra. This is a less optimal configuration with respect to minimizing $\mathrm{A}^{\prime}-\mathrm{A}^{\prime}$ repulsion than the corner-linked configuration adopted in the sodium phases. However, this edge-shared connectivity allows the tilting distortions of the $\mathrm{MO}_{6}$ network to decrease the size of the occupied tetrahedral cation sites and optimize the coordinations of the A' cations, resulting in a near ideal coordination environment for the $\mathrm{Li}$ cations. Thus we propose that the differing structures adopted by the $\mathrm{NaNdM}_{2} \mathrm{O}_{7}$ and $\mathrm{LiNdM}_{2} \mathrm{O}_{7}$ phases arise from a competition between minimizing the $\mathrm{A}^{\prime}-\mathrm{A}^{\prime}$ repulsion and optimizing the $\mathrm{A}^{\prime}$-cation coordination site, with the former being the dominant factor for the $\mathrm{Na}$ phases and the latter for the $\mathrm{Li}$ phases.

This idea can be supported by examining the energy minimized, hypothetical structures of the $\mathrm{Na}$ and $\mathrm{Li}$ phases with the alternate structure type. That is to say $\mathrm{NaNdNb}_{2} \mathrm{O}_{7}$ with a $B 2 \mathrm{~cm}$ symmetry structure and $\mathrm{LiNdNb}_{2} \mathrm{O}_{7}$ with a $P 4_{2} / \mathrm{mnm}$ structure. As shown in Tables S4 and S5, the energy minimized, hypothetical $\mathrm{B} 2 \mathrm{~cm}$ structure of $\mathrm{NaNdNb}_{2} \mathrm{O}_{7}$ adopts a much more distorted $\mathrm{MO}_{6}$ framework than the experimental structure. This increased distortion acts to contract the size of the $\mathrm{Na}$ coordination site raising the $\mathrm{Na} \mathrm{BVS}$ to a value of +1.23 . However despite this improvement to the local $\mathrm{Na}-\mathrm{O}$ bonding, this $B 2 \mathrm{~cm}$ configuration is $88 \mathrm{meV} /$ formula unit less stable than an equivalent, energy minimized structure with $P 4_{2} / m n m$ symmetry. This is consistent with the idea that unfavorable increase Na-Na repulsion, which occurs when the $\mathrm{Na}$ cations are arranged in an edge-sharing configuration within the $\mathrm{B} 2 \mathrm{~cm}$ structure, outweighs the improved $\mathrm{Na}-\mathrm{O}$ bonding arising from contraction of the $\mathrm{Na}$ coordination site, making the $P 4_{2} / m n m$ symmetry structure the optimal configuration for $\mathrm{NaNdNb}_{2} \mathrm{O}_{7}$

Similarly, inspection of the energy minimized, hypothetical $\mathrm{P}_{2} / \mathrm{mnm}$ symmetry structure for $\mathrm{LiNdNb}_{2} \mathrm{O}_{7}$ (Tables $\mathrm{S} 6$ and S7) reveals it is $289 \mathrm{meV} /$ formula unit less stable than the equivalent energy minimized $B 2 \mathrm{~cm}$ phase. This lower stability can be attributed to the significant expansion of the Li coordination site which occurs on switching to the $P 4_{2} / \mathrm{mnm}$ symmetry structure. The resulting BVS value for $\mathrm{Li}(0.73)$ in this site is too small to be chemically sensible, indicating this site is much too large to accommodate $\mathrm{Li}^{+}$(it is essentially only three-coordinate), consistent with the proposal that optimizing the size of the $\mathrm{Li}$ coordination site has a larger impact on the energy of $\mathrm{LiNdM}_{2} \mathrm{O}_{7}$ phases than the increase $\mathrm{Li}-\mathrm{Li}$ repulsion arising from the edge-sharing of $\mathrm{LiO}_{4}$ units, making the $\mathrm{B2} \mathrm{cm}$ symmetry structure the optimal configuration for $\mathrm{LiNdNb}_{2} \mathrm{O}_{7}$.

\section{Conclusion}

The contrasting balance between minimizing the A'-A' cation repulsions and optimizing the $\mathrm{A}^{\prime}$ coordination reached by the lithium and sodium phases has echoes of the similar balance in the $\mathrm{A}^{\prime} \mathrm{NdM}_{2} \mathrm{O}_{7}\left(\mathrm{~A}^{\prime}=\mathrm{Rb}, \mathrm{Cs}\right)$ Dion-Jacobson phases between minimizing $\mathrm{O}-\mathrm{O}$ repulsion and optimizing the $\mathrm{A}^{\text {' }}$ coordination. ${ }^{28}$ Together these observations suggest that the tilting distortions of $\mathrm{A}^{\prime} \mathrm{AB}_{2} \mathrm{O}_{7}$ phases with either RuddlesdenPopper or Dion-Jacobson frameworks can be tuned by careful selection of the A' cation. This feature is further emphasized by observing that in order for the tilting distortions of the $\mathrm{MO}_{6}$ network to contract the lithium coordination site uniformly, the $x$ and $y$ tilts in adjacent perovskite double sheets have to have the opposite sign, ie. $a^{\mathrm{p}} b^{\mathrm{q}} c^{\mathrm{r}} /-\left(a^{\mathrm{p}} b^{\mathrm{q}}\right) \pm c^{\mathrm{r}}$. Thus it can be seen that the small size of the lithium cations directs the lattice into the polar $a^{-} a^{-} c^{+} /-\left(a^{-} a^{-} c^{+}\right)$tilting distortion. It therefore seems likely that by careful selection of A' cations, a series of novel polar configurations can be constructed.

\section{ASSOCIATED CONTENT}

Supporting Information. Symmetry analysis of $n=2$ Ruddlesden-Popper phases; Extinction conditions of $\mathrm{LiNdM}_{2} \mathrm{O}_{7}$ and $\mathrm{NaNdM}_{2} \mathrm{O}_{7}$ phases; Comparison of constrained and unconstrained $P 2 \mathrm{~cm}$ models of $\mathrm{LiNdM}_{2} \mathrm{O}_{7}$ phases; Fitted neutron powder diffraction data from the refinement of $\mathrm{LiNdM}_{2} \mathrm{O}_{7}$ and $\mathrm{NaNdM}_{2} \mathrm{O}_{7}$ phases; Tolerance factor analysis for tetrahedral $\mathrm{A}^{\prime}$-cation site; Energy minimized structures of hypothetical $B 2 \mathrm{~cm}$ symmetry $\mathrm{NaNdNb}_{2} \mathrm{O}_{7}$ and $P 4_{2} / m n m$ symmetry $\mathrm{LiNdNb}_{2} \mathrm{O}_{7}$. This material is available free of charge via the Internet at http://pubs.acs.org.

\section{AUTHOR INFORMATION}

\section{Corresponding Author \\ michael.hayward@chem.ox.ac.uk nbenedek@cornell.edu}

\section{Author Contributions}

The manuscript was written through contributions of all authors.

\section{Funding Sources}

Any funds used to support the research of the manuscript should be placed here (per journal style).

\section{ACKNOWLEDGMENT}

Experiments at the Diamond Light Source were performed as part of the Block Allocation Group award "Oxford Solid State Chemistry BAG to probe composition-structure-property relationships in solids" (EE13284). Experiments at the ISIS pulsed neutron facility were supported by a beam time allocation from the STFC (RB1620305). NAB was supported by the National Science Foundation (NSF) via Grant DMR-1550347. GK was supported by the NSF via Grant DMR-1719875. DMH was supported by an NSF Graduate Research Fellowship. This work used the highperformance computing facilities of the Cornell Center for Advanced Computing. WZ and PSH thank the Welch Foundation (Grant E-1457) and the NSF (DMR-1503573) for support.

\section{REFERENCES}

1. Lines, M. E.; Glass, A. M., Principles and Applications of Ferroelectrics and Related Materials. Oxford University Press: Oxford, 1991.

2. Nye, F. J., Physical Properties of Crystals. Oxford University Press: Oxford, UK, 1957.

3. Halasyamani, P.; Poeppelmeier, K. R., Noncentrosymetric oxides. Chem. Mater. 1998, 10, 2753-2769.

4. Cohen, R. E., Origin of Ferroelectricity in Perovskite Oxides. Nature 1992, 358, 136-138.

5. Kang, S. K.; Tang, H.; Albright, T. A., Structures for $\mathrm{d}^{0}$ $\mathrm{Ml}_{6}$ and $\mathrm{Ml}_{5}$ Complexes. J. Am. Chem. Soc. 1993, 115, 1971-1981.

6. Kunz, M.; Brown, I. D., Out-of-Center Distortions around Octahedrally Coordinated $\mathrm{d}^{0}$ Transition-Metals. J. Solid State Chem. 1995, 115, 395-406.

7. Pearson, R. G., The 2nd-Order Jahn-Teller Effect. Theochem-Journal of Molecular Structure 1983, 12, 25-34.

8. Lefebvre, I.; Lannoo, M.; Allan, G.; Ibanez, A.; Fourcade, J.; Jumas, J. C.; Beaurepaire, E., Electronic-Properties of Antimony Chalcogenides. Phys. Rev. Lett. 1987, 59, 2471-2474.

9. Lefebvre, I.; Szymanski, M. A.; Olivier-Fourcade, J.; Jumas, J. C., Electronic Structure of Tin Monochalcogenides from SnO to SnTe. Phys. Rev. B 1998, 58, 1896-1906.

10. Seshadri, R.; Hill, N. A., Visualizing the Role of Bi $6 \mathrm{~s}$ "Lone Pairs" in the Off-Center Distortion in Ferromagnetic $\mathrm{BiMnO}_{3}$. Chem. Mater. 2001, 13, 2892-2899. 
11. Stoltzfus, M. W.; Woodward, P. M.; Seshadri, R.; Klepeis, J. H.; Bursten, B., Structure and Bonding in $\mathrm{SnWO}_{4}, \mathrm{PbWO}_{4}$, and $\mathrm{BiVO}_{4}$ : Lone Pairs vs Inert Pairs. Inorg. Chem. 2007, 46, 3839-3850.

12. Watson, G. W.; Parker, S. C., Origin of the Lone Pair of alpha-PbO from Density Functional Theory Calculations. J. Phys. Chem. B 1999, 103, 1258-1262.

13. Watson, G. W.; Parker, S. C.; Kresse, G., Ab Initio Calculation of the Origin of the Distortion of Alpha-PbO. Phys. Rev. $B$ 1999, 59, 8481-8486.

14. Hill, N. A., Why Are There So Few Magnetic Ferroelectrics. J. Phys. Chem. B 2000, 104, 6694-6709.

15. Benedek, N. A.; Fennie, C. J., Hybrid Improper Ferroelectricity: A Mechanism for Controllable PolarizationMagnetization Coupling. Phys. Rev. Lett. 2011, 106, 107204.

16. Mulder, A. T.; Benedek, N. A.; Rondinelli, J. M.; Fennie, C. J., Turning $\mathrm{ABO}_{3}$ Antiferroelectrics into Ferroelectrics: Design Rules for Practical Rotation-Driven Ferroelectricity in Double Perovskites and $\mathrm{A}_{3} \mathrm{~B}_{2} \mathrm{O}_{7}$ Ruddlesden-Popper Compounds. Advanced Functional Materials 2013, 23, 4810-4820.

17. Benedek, N. A.; Mulder, A. T.; Fennie, C. J., Polar octahedral rotations: A path to new multifunctional materials. J. Solid State Chem. 2012, 195, 11-20.

18. Bousquet, E.; Dawber, M.; Stucki, N.; Lichtensteiger, C.; Hermet, P.; Gariglio, S.; Triscone, J. M.; Ghosez, P., Improper Ferroelectricity in Perovskite Oxide Artificial Superlattices. Nature 2008, 452, 732-U4.

19. Benedek, N. A.; Rondinelli, J. M.; Djani, H.; Ghosez, P.; Lightfoot, P., Understanding Ferroelectricity in Layered Perovskites: New Ideas and Insights From Theory and Experiments. Dalton Trans. 2015, 44, 10543-10558.

20. Bostrom, H. L. B.; Senn, M. S.; Goodwin, A. L., Recipes for improper ferroelectricity in molecular perovskites. Nature Communications 2018, 9, 1-7.

21. Young, J.; Stroppa, A.; Picozzi, S.; Rondinelli, J. M., Anharmonic lattice interactions in improper ferroelectrics for multiferroic design. J. Phys.: Condens. Matter 2015, 27, 283202.

22. Oh, Y. S.; Luo, X.; Huang, F. T.; Wang, Y. Z.; Cheong, S. W., Experimental demonstration of hybrid improper ferroelectricity and the presence of abundant charged walls in $(\mathrm{Ca}, \mathrm{Sr})_{3} \mathrm{Ti}_{2} \mathrm{O}_{7}$ crystals. Nat. Mater. 2015, 14, 407-413.

23. Liu, M. F.; Zhang, Y.; Lin, L. F.; Lin, L.; Yang, S. W.; Li, X.; Wang, Y.; Li, S. Z.; Yan, Z. B.; Wang, X. Z.; Li, X. G.; Dong, S.; Liu, J. M., Direct observation of ferroelectricity in $\mathrm{Ca}_{3} \mathrm{Mn}_{2} \mathrm{O}_{7}$ and its prominent light absorption. Appl. Phys. Lett. 2018, 113, 022902.

24. Yoshida, S.; Fujita, K.; Akamatsu, H.; Hernandez, O.; Sen Gupta, A.; Brown, F. G.; Padmanabhan, H.; Gibbs, A. S.; Kuge, T.; Tsuji, R.; Murai, S.; Rondinelli, J. M.; Gopalan, V.; Tanaka, K., Ferroelectric $\mathrm{Sr}_{3} \mathrm{Zr}_{2} \mathrm{O}_{7}$ : Competition between Hybrid Improper Ferroelectric and Antiferroelectric Mechanisms. Advanced Functional Materials 2018, 28, 1801856.

25. Dion, M.; Ganne, M.; Tournoux, M., The New Phase Families $\mathrm{M}^{\mathrm{I}} \mathrm{M}^{\mathrm{II} 2} \mathrm{Nb}_{3} \mathrm{O}_{10}$ with Perovskite Sheets. Mater. Res. Bull. 1981, 16, 1429-1435.

26. Jacobson, A. J.; Johnson, J. W.; Lewandowski, J. T., Interlayer Chemistry between Thick Transition-Metal Oxide Layers Synthesis and Intercalation Reactions of $\mathrm{K}\left[\mathrm{Ca}_{2} \mathrm{Na}_{\mathrm{n}-3} \mathrm{Nb}_{\mathrm{n}} \mathrm{O}_{3 \mathrm{n}+1}\right](3<\mathrm{n}<$ 7). Inorg. Chem. 1985, 24, 3727-3729.

27. Benedek, N. A., Origin of Ferroelectricity in a Family of Polar Oxides: The Dion-Jacobson Phases. Inorg. Chem. 2014, 53, 3769-3777.

28. Zhu, T.; Cohen, T.; Gibbs, A. S.; Zhang, W. G.; Halasyamani, P. S.; Hayward, M. A.; Benedek, N. A., Theory and Neutrons Combine To Reveal a Family of Layered Perovskites without Inversion Symmetry. Chem. Mater. 2017, 29, 9489-9497.

29. Strayer, M. E.; Gupta, A. S.; Akamatsu, H.; Lei, S.; Benedek, N. A.; Gopalan, V.; Mallouk, T. E., Emergent Noncentrosymmetry and Piezoelectricity driven by oxygen octahedral roatations in $\mathrm{n}=2$ Dion-jacobson phase layered perovskites. Advanced Functional Materials 2016, 26, 1930-1937.

30. Schaak, R. E.; Mallouk, T. E., Perovskites by design: A toolbox of solid-state reactions. Chem. Mater. 2002, 14, 1455-1471.
31. Hayward, M. A., Soft chemistry synthesis of oxides. In Comprehensive Inorganic Chemistry II, Reedijk, J.; Poeppelmeier, K R., Eds. Elsevier: Oxford, 2013; Vol. 2, pp 417-453.

32. Ranmohotti, K. G. S.; Josepha, E.; Choi, J.; Zhang, J. X.; Wiley, J. B., Topochemical Manipulation of Perovskites: LowTemperature Reaction Strategies for Directing Structure and Properties. Adv. Mater. 2011, 23, 442-460.

33. Gopalakrishnan, J.; Bhat, V.; Raveau, B., $\mathrm{A}^{\mathrm{I}} \mathrm{LaNb}_{2} \mathrm{O}_{7}$ - a New Series of Layered Perovskites Exhibiting Ion-Exchange and Intercalation Behavior. Mater. Res. Bull. 1987, 22, 413-417.

34. Toda, K.; Sato, M., Synthesis and structure determination of new layered perovskite compounds, $\mathrm{ALaTa}_{2} \mathrm{O}_{7}$ and $\mathrm{ACa}_{2} \mathrm{Ta}_{3} \mathrm{O}_{10}$ (A=Rb, Li). J. Mater. Chem. 1996, 6, 1067-1071.

35. Josepha, E. A.; Farooq, S.; Mitchell, C. M.; Wiley, J. B. Synthesis and thermal stability studies of a series of metastable DionJacobson double-layered neodymium-niobate perovskites. J. Solid State Chem. 2014, 216, 85-90.

36. Mahler, C. H.; Cushing, B. L.; Lalena, J. N.; Wiley, J. B., Divalent ion exchange of alkaline-earth cations into the triple-layered perovskite $\mathrm{RbCa}_{2} \mathrm{Nb}_{3} \mathrm{O}_{10}$. Mater. Res. Bull. 1998, 33, 1581-1586.

37. Kodenkandath, T. A.; Kumbhar, A. S.; Zhou, W. L.; Wiley, J. B., Construction of copper halide networks within layered perovskites. Syntheses and characterization of new low-temperature copper oxyhalides. Inorg. Chem. 2001, 40, 710-714.

38. Kodenkandath, T. A.; Lalena, J. N.; Zhou, W. L. L.; Carpenter, E. E.; Sangregorio, C.; Falster, A. U.; Simmons, W. B.; O'Connor, C. J.; Wiley, J. B., Assembly of metal-anion arrays within a perovskite host. Low-temperature synthesis of new layered copperoxyhalides, $(\mathrm{CuX}) \mathrm{LaNb}_{2} \mathrm{O}_{7}, \mathrm{X}=\mathrm{Cl}$, Br. J. Am. Chem. Soc. 1999, 121 10743-10746.

39. Ranmohotti, K. G. S.; Montasserasadi, M. D.; Choi, J.; Yao, Y.; Mohanty, D.; Josepha, E. A.; Adireddy, S.; Caruntu, G.; Wiley, J. B., Room temperature oxidative intercalation with chalcogen hydrides: Two-step method for the formation of alkalimetal chalcogenide arrays within layered perovskites. Mater. Res. Bull. 2012, 47, 1289-1294.

40. Suzuki, H.; Notsu, K.; Takeda, Y.; Sugimoto, W.; Sugahara, Y., Reactions of alkoxyl derivatives of a layered perovskite with alcohols: Substitution reactions on the interlayer surface of a layered perovskite. Chem. Mater. 2003, 15, 636-641.

41. Takeda, Y.; Momma, T.; Osaka, T.; Kuroda, K.; Sugahara, $\mathrm{Y}$., Organic derivatives of the layered perovskite $\mathrm{HLaNb}_{2} \mathrm{O}_{7} \cdot \mathrm{xH}_{2} \mathrm{O}$ with polyether chains on the interlayer surface: characterization, intercalation of $\mathrm{LiClO}_{4}$, and ionic conductivity. J. Mater. Chem. 2008, 18, 3581-3587.

42. Takeda, Y.; Suzuki, H.; Notsu, K.; Sugimoto, W Sugahara, Y., Preparation of a novel organic derivative of the layered perovskite bearing $\mathrm{HLaNb}_{2} \mathrm{O}_{7} \cdot \mathrm{nH}_{2} \mathrm{O}$ interlayer surface trifluoroacetate groups. Mater. Res. Bull. 2006, 41, 834-841.

43. Sato, M.; Abo, J.; Jin, T., Structure examination of $\mathrm{NaLaNb}_{2} \mathrm{O}_{7}$ synthesized by soft chemistry. Solid State Ionics 1992, 57, 285-293.

44. Larson, A. C.; Von Dreele, R. B. General Structure Analysis System, Los Alamos National Laboratory Report LAUR 86748: 2000.

45. Ok, K. M.; Chi, E. O.; Halasyamani, P. S., Bulk characterization methods for non-centrosymmetric materials: secondharmonic generation, piezoelectricity, pyroelectricity, and ferroelectricity. Chem. Soc. Rev. 2006, 35, 710-717.

46. Perdew, J. P.; Ruzsinszky, A.; Csonka, G. I.; Vydrov, O. A.; Scuseria, G. E.; Constantin, L. A.; Zhou, X. L.; Burke, K. Restoring the density-gradient expansion for exchange in solids and surfaces. Phys. Rev. Lett. 2008, 100, 136406.

47. Blochl, P. E., Projector augmented-wave method. Phys. Rev. B 1994, 50, 17953-17979.

48. Kresse, G.; Joubert, D., From ultrasoft pseudopotentials to the projector augmented-wave method. Phys. Rev. B 1999, 59, 17581775 .

49. Kresse, G.; Hafner, J., Ab-initio molecular-dynamics for liquid-metals. Phys. Rev. B 1993, 47, 558-561.

50. Kresse, G.; Furthmuller, J., Efficient iterative schemes for ab initio total-energy calculations using a plane-wave basis set. Phys Rev. B 1996, 54, 11169-11186. 
51. Kresse, G.; Furthmuller, J., Efficiency of ab-initio total energy calculations for metals and semiconductors using a planewave basis set. Computational Materials Science 1996, 6, 15-50.

52. Kresse, G.; Hafner, J., Ab-initio Molecular Dynamics Simulation of the Liquid-metal Amorphous-semiconductor Transition in Germanium. Phys. Rev. B 1994, 49, 14251-14269.

53. Aleksandrov, K. S.; Bartolome, J., Octahedral Tilt Phases in Perovskite-like Crystals with Slabs Containing an Even Number of Octahedral Layers. J. Phys.: Condens. Matter 1994, 6, 8219-8235.

54. Campbell, B. J.; Stokes, H. T.; Tanner, D. E.; Hatch, D. M., ISODISPLACE: a web-based tool for exploring structural distortions. J. Appl. Crystallogr. 2006, 39, 607-614.

55. Brese, N. E.; O'Keeffee, M., Bond-Valence Parameters for Solids. Acta Crystallogr., Sect. B : Strucut. Sci. 1991, B47, 192-197.

56. Brown, I. D.; Altermatt, D., Bond-Valence Parameters Obtained from a Systematic Analysis of the Inorganic Crystal Structure Database. Acta Crystallogr., Sect. B : Strucut. Sci. 1985, B41, 244-247.

57. Goldschmidt, V. M., Die Gesetze der Krystallochemie. Naturwissenschaften 1926, 14, 477-485.

58. Shannon, R. D., Revised effective ionic radii. Acta Cryst. 1976, A32, 751-766.

59. Pauling, L., The Principles Determining the Strucutre of Complex Ionic Crystals. J. Am. Chem. Soc. 1929, 51, 1010-1026. 


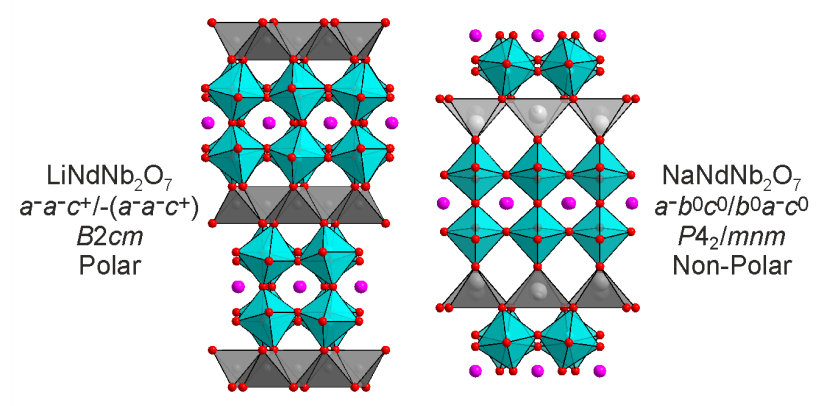

